\title{
AC 2010-265: STUDENT PRECONCEPTIONS AND HEURISTICS IN LEARNING DESIGN
}

\section{Steven Zemke, Gonzaga University}

Steven Zemke is Associate Professor and Chair of Mechanical Engineering at Gonzaga University in Spokane Washington. He oversees the curriculum for all Mechanical design courses and teaches sections of each. His research area is pedogogy of design. Prior to teaching, he was a design engineer for 25 years at Hewlett Packard, General Instruments, and Bell Telephone Labs. 


\section{Student Preconceptions and Heuristics in Learning Design}

\section{Introduction}

One conundrum in teaching design is that students will learn and practice a design method and later abandon that method in favor of a "seat-of-the-pants" approach. It is as if they had not learned the method initially. This sequence of learning and then abandoning begs a question: "What went wrong in the initial learning?"

One major finding in the cognitive literature offers an answer to this question. The naïve preconceptions that students bring to a subject directly interfere with their learning. ${ }^{1,2}$ These preconceptions can interfere so strongly that some students don't actually learn. When the learning session concludes, the students' understanding reverts to their prior misconceptions. Consequently, in order for the new learning to take root, those preconceptions must be engaged and addressed during the learning. It seems reasonable that preconceptions affect design learning as well.

A number of disciplines (most notably physics ${ }^{3}$ ) have extensively identified common student misconceptions. These lists of misconceptions are discipline specific, that is, misconceptions in one discipline do not identify misconceptions in an unrelated discipline. However, once misconceptions are classified within a discipline, instructors can engage them as part of teaching the course.

This perspective highlights a fundamental hurdle for design instructors: students' preconceptions about how to do design are not clearly identified. Without this knowledge, design instructors cannot systematically engage and address these preconceptions. Consequently, student learning in design is hampered.

The intent of this study was to identify preconceptions students bring to design and to frame them in terms of the cognitive literature. The preconceptions were explored using two sequential focus group discussions based on the questions, "What did you learn about design?" and "What did you need to un-learn to do design?"

The participants in this study had completed an intermediate level design class. The class used multiple design-build-test projects supported by lectures to teach design. The semester following this class, one design team was selected for the focus group discussions because they initially demonstrated low design ability but performed at a high level by the end of the term.

The data supported two findings:

1. Knowledge flows back to students from their own design as real-world constraints are enforced. As the students learn from their design, they develop a conceptual framework of how their design works or does not work. As this conceptual framework develops, misconceptions can also develop within that framework. These misconceptions can be very robust, require multiple interventions to resolve, and interfere with correct understanding of 
their design. Furthermore, these misconceptions can prompt unsuccessful design process strategies, which may deter learning the design process.

2. Students may follow a decision-making heuristic of "satisficing,", that is choosing the first "good enough" option, while implementing their designs. This heuristic is used by people in everyday life to streamline decisions when they lack complete information. In contrast many design textbooks describe a much more formal decision-making process. This finding suggests that the cognitive literature in heuristics and decision-making can provide a theoretical foundation for understanding why students have difficulty enacting the design process as described in textbooks.

\section{Literature}

Students bring many preconceptions to the classroom. ${ }^{1,2}$ Some of these preconceptions are naïve, while others may be mature. However, no matter what the nature of students' preconceptions, they learn new knowledge by actively building upon their preconceptions. This constructivist view of learning ${ }^{1,2,5}$ has emerged in the past few decades and is supported by a broad range of studies in cognition and education.

One implication of the constructivist view is that students' preconceptions directly affect learning. Well-developed and correct preconceptions aid learning, whereas incorrect preconceptions can seriously impede learning. Consequently, excellent teaching directly engages these preconceptions. ${ }^{1,2}$ Furthermore, if preconceptions are not engaged, students revert to their former ways of thinking after the learning experience ends. For example, a student in physics may revert to an impetus theory of causation even after taking a class in Newtonian dynamics. ${ }^{3}$

Most students enter their first design course with little design experience. Superficially, this suggests that students have few preconceptions about design. The students may be "blank slates." However, this is not the case. Humans start learning from infancy ${ }^{1,2}$ by making sense of experiences. By the time students enter college design classes, they have a myriad of experiences and understandings to draw upon. Though these experiences may not relate directly to design, they have many experiences of solving open-ended problems. Since design problems are typically open-ended, students can draw upon their open-ended problem solving experiences. Consequently, though students may not have direct design experience, they have other experiences that they apply when given a design problem. These experiences can embody design preconceptions.

\section{What form will student design preconceptions take?}

The cognitive literature distinguishes between declarative and procedural knowledge. ${ }^{4}$ Declarative knowledge can be stated and is known explicitly. This type of knowledge answers questions such as, "What is Newton's first law of motion?" The prevailing models conceive of declarative knowledge in units of "concepts" that fit within "categories" which are organized into "schema." For example an apple (concept) is a fruit (category) which is part of a balanced diet (schema). Engineering textbooks are full of this sort of knowledge. 
In contrast, procedural knowledge is used to "do things," is often much harder to state, and is frequently implicit. For example, most people can tie their shoes, but have a hard time describing it in steps. Though how to tie a shoe can be described in explicit steps that can be stated, the mind simply does not organize the information this way.

Student preconceptions about design certainly include both declarative and procedural knowledge. For example, a student may state, "The first step is to come up with many possible solutions to the design," (declarative knowledge). On the other hand, the same student may enact a strategy of, "if a solution looks plausible, then stop looking for other solutions until the solution in hand is tested" (procedural knowledge).

Procedural knowledge will manifest itself in students' actions as they do design work. Much of design work is solving open-ended problems. When confronted with open-ended problems people (in general) employ heuristics to help solve them. Heuristics are "mental shortcuts...informal, intuitive, speculative strategies that sometimes lead to an effective solution and sometimes do not." 4 Note, heuristics are strategies, hence they are primarily procedural in nature. So procedural knowledge, embedded in heuristics, is a potential source of student misconceptions.

\section{Methods}

\section{Course content}

This study was conducted in an intermediate level mechanical engineering design class. The class presented the design process as a series of steps that are completed primarily in order with occasional iteration to modify previous work. The steps were:

1. Define what the engineered solution must do.

2. Generate alternative concept solutions.

3. Assess the alternatives and choose the best.

4. Detail the design in engineering documents (sketches early in the semester, 3D CAD for the final project).

5. Fabricate a prototype.

6. Test the prototype and log design deficiencies.

7. Redesign the solution, etc.

\section{Course Projects}

The course used short lab projects with supplemental lectures to teach design. The first lab project involved designing, building, and testing a machine that would individually flip and restack poker chips (chip-flipper 1). Student machines were made of corrugated cardboard and hot-melt glue. These construction materials avoided lengthy fabrication cycles and allowed the students to focus on the function of their machine. Following the testing of their first prototype, the students were given a rubric to determine the cost of their machine (cost per feature on each part; cost per assembly operation). The students then re-designed it and built a prototype to reduce the cost and address any functional deficiencies.

In the next lab project the students designed, built, and tested another poker chip manipulator except that it added collating chips from two separate stacks. Following testing, the students 
conducted a design review to assess the strengths and weaknesses of each other's designs. The students then re-designed and built another prototype to address functional deficiencies.

The final project of the semester required two teams to design and build a mechanism to loft a camera with a water rocket and take photos as it descended on a parachute. The first team designed and built a mechanism to eject the camera at the apex of its flight. The second team designed and built a mechanism to turn on the camera and depress the shutter button once a second.

\section{Course structure}

The class had 23 students who were assigned to teams of 4 the entire semester. Four months after the class concluded two sequential focus group discussions were held with one of the teams. The specific team was chosen because their performance consistently increased throughout the semester and their teamwork appeared strong. Since their teamwork was strong, factors related to poor working relationships would not overshadow the other learning.

\section{Focus discussion questions}

The focus group discussions used the following six questions:

1. What did you learn in the design class?

2. What new procedures or methods did you learn in the design class?

3. What new habits did you learn in the design class?

4. Did you learn anything about yourself while doing design?

5. What did you need to unlearn in design?

The discussions were one hour long and included pizza as a thank you. The first session covered the first four questions. The second session covered the remaining questions and then reexplored ideas that surfaced during the first session. Both sessions were taped and notes were taken. Unfortunately, the microphone was inadvertently turned off before the first session, so first session data is based only on the notes of the time. The discussion for the second session was transcribed. The notes and transcripts form the data for this study.

\section{Focus group protocol}

The questions were intended to frame the discussion, but not constrain it. To do this framing, the researcher posed the first question and simply waited for the students to respond. A natural discussion developed. One student responded. Another student chimed in or elaborated on the idea presented. Yet another student provided more context for understanding the responses. Frequently, one student's response would initiate a related set of ideas from another student. Throughout the discussions, the researcher asked for clarification or asked the students to elaborate more on relationship between ideas expressed. On a few occasions the researcher compared earlier responses to related later responses and asked for deeper explanations. As responses from each question dwindled, the researcher would initiate the next question.

\section{Data coding for themes}

The initial identification of themes happened in two ways as the discussions progressed. First, each question naturally elicited responses within the scope of the question. Therefore, the questions were initially chosen to inform the intent of the study. Hence each question surfaced 
related themes. Second, the researcher actively pursued the themes that emerged as the students responded. Since these themes were couched within a discussion, related themes were frequently clustered in the student dialogue.

Broader themes were identified in two ways. First, the researcher asked for clarification and additional perspectives any time the student discussion touched on misconceptions, how they could develop, or heuristics. At these points the researcher would contrast ideas in the current discussion with notes from earlier in the discussion and ask for comment. Second, after the transcripts were completed, the researcher read and reread them to identify other recurring themes.

\section{Results: student interaction and responses to focus questions}

Student interactions during the focus discussions

As mentioned earlier, the students often elaborated on each other's ideas to provide a multivoiced understanding of their reflections. All discussions were relaxed and unusually balanced. In the transcript of the second session the two young men responded 30 and 33 times respectively and the two young women responded 34 and 44 times respectively. Though the young men would initially answer questions more quickly, the young women would add perspective after a conversation turn or two. At no time did the researcher notice any student dominating the discussion. Rather the students built on each other's ideas with their individual reflections.

Question 1: What did you learn in the design class?

The students said the primary thing they learned was that "design is not tidy." They explained that though the textbook description of the design process appeared quite orderly, their design experience was messy. For example, a project schedule appears orderly, however following the schedule is difficult.

Another messy aspect is that design required far more testing than they expected. Whereas the students imagined that their design was "perfect," in fact it required significant testing to root out all the problems. The students noted that requiring their prototypes to work enforced real-world constraints and that this was the first class that actually applied real-world constraints. For example, in their prior CAD class an impractical design was fine because it still looked great on the computer screen.

Question 2: What new procedures or methods did you learn in the design class?

The students said they learned procedures that were explicitly taught in the class. For example, they developed a habit of thinking through a concept to the details of its implementation. They cited the rigor of completing the Ishikawa failure diagram taught in class as helping them to pay attention to details.

They also adopted procedures not taught in the class. These procedures related primarily to teamwork. They had to learn to negotiate with teammates concerning favored concepts. They had to adopt strategies to insure complete communication. They had to set boundaries when working with their companion team on the final project. 
Question 3: What new habits did you learn in the design class?

The students identified three design habits they learned. The first habit was to "be a concept doubter." Don't believe that a concept will work until proven. Second, they developed a habit of understanding the design as a whole while decomposing it into "little functions." Third, the developed the team habit of planning all communication.

Question 4: Did you learn anything about yourself while doing design?

The responses for "learning about yourself" identified two expectations the students brought to the class. First, the students expected their ideas should work, as implemented, the first time. One student noted that consumer products always work right out of the box, so she naïvely expected her ideas to work the first time.

The students also expected their initial ideas about teamwork to work. At first they conceived of teamwork as "divide and conquer." Later they realized that individual work must be reintegrated to form a team result.

Question 5: What did you need to unlearn in design?

This question about "unlearning" began the second discussion. Throughout the discussion, the investigator periodically rephrased the student responses in terms of unlearning to test whether the students felt they truly had to unlearn something.

Two related naïve ideas about how design is done were identified as needed to be unlearned. First was the idea that careful thought will lead to a functioning design on the first try. The students contrasted their experience of needing to solve one prototype problem after another against their initial expectation that the prototype should work.

The related idea to be unlearned was that their first (workable) idea was good enough. The students mentioned that even though they explicitly knew their first idea would not be their best idea, they still pursued implementing it. As one student explained "because normally, whenever you work on something... your first idea you take it, you run with it, and that's just kind of what you use...." When asked how they developed this habit of running with the first idea they mused that using their first idea naturally developed in the course of regular school work. Using the first idea was an expedient to finishing homework on time. They had even developed ways to succeed with a "run with the first idea" strategy in other courses. In CAD design, put effort into one "good" (first workable) concept and then merely generated "fake" alternatives to complete the assignment. In English papers, choose a thesis (their first idea) and develop the thesis by selectively interpreting selected quotes from a text.

The students were very certain they had to unlearn these ideas. They cited several experiences that demonstrated that to learn it rightly, they had to actively resist a faulty inclination. When asked how they unlearned running with their first idea, the students reported that it was realworld constraints that forced the issue. “...We had tons of problems...we'd fix something [and] there was something else that needed to be fixed." The students also reported that on the design of a specific spring it took repeated discussions with the instructor and with the machinist before they even recognized the problematic design, let alone address it. 
Other themes and responses

The students noted that initially "building" seemed a better approach than planning, sketching, or running a quick experiment to set bounds on a design. As one student stated, "...that [habit] we had to unlearn is that it's easier to fix things when they're already physically existing. So, like, if we just built it, we kind of figured we'd just figure things out along the way."

One recurring theme through all discussions was that design was far more "messy" than originally imagined. They said that initially they understood the problem and solution much too simply. They didn't pay enough attention to constraints such as how the parts would be made or the realistic tolerances the parts would have. They considered failures only in global terms rather than by decomposing functions.

\section{Discussion}

Naïve expectations and linear flow of knowledge

Early in the semester, the students naively thought that their ideas would be "perfect." One student stated, "Obviously we always expected that if we really thought about our concepts and thought about how we would put everything together, that when it got put together it would work." Another student stated, "You know, you always think it's going to work...."

The notion that their ideas were perfect spanned several areas. For example, they thought their planning was robust, "If you set a plan out perfectly... everything will be perfect." They thought their design concepts were sound, "...when it got put together it would work." Their conception of teamwork was "divide and conquer"; only later did they realize that results had to be reintegrated. They thought their design detailing was fine without regard for part fabrication, “...just think of a shape and extrude it... you don't have to think about how...to make [it]...." Of course they learned that their perfect ideas were not perfect, "So we had tons of problems...."

The students' behaviors suggest that initially they viewed design knowledge as a linear flow of information without a need for iteration or additional learning. Though the instruction and the textbook both emphasized the process was highly iterative, they still acted as though information only flowed forward. For example, they designed and built their first machine completely without testing subcomponents along the way. They constructed a "perfect" schedule and were surprised when they couldn't follow it. They fully detailed sheet metal parts and expected the machinist could make them as designed. All of these behaviors depend on the notion that the initial idea is sufficient in and of itself and will not change due to unforeseen problems. This naïve conception that design information flows only forward is diagrammed in Figure 1. 

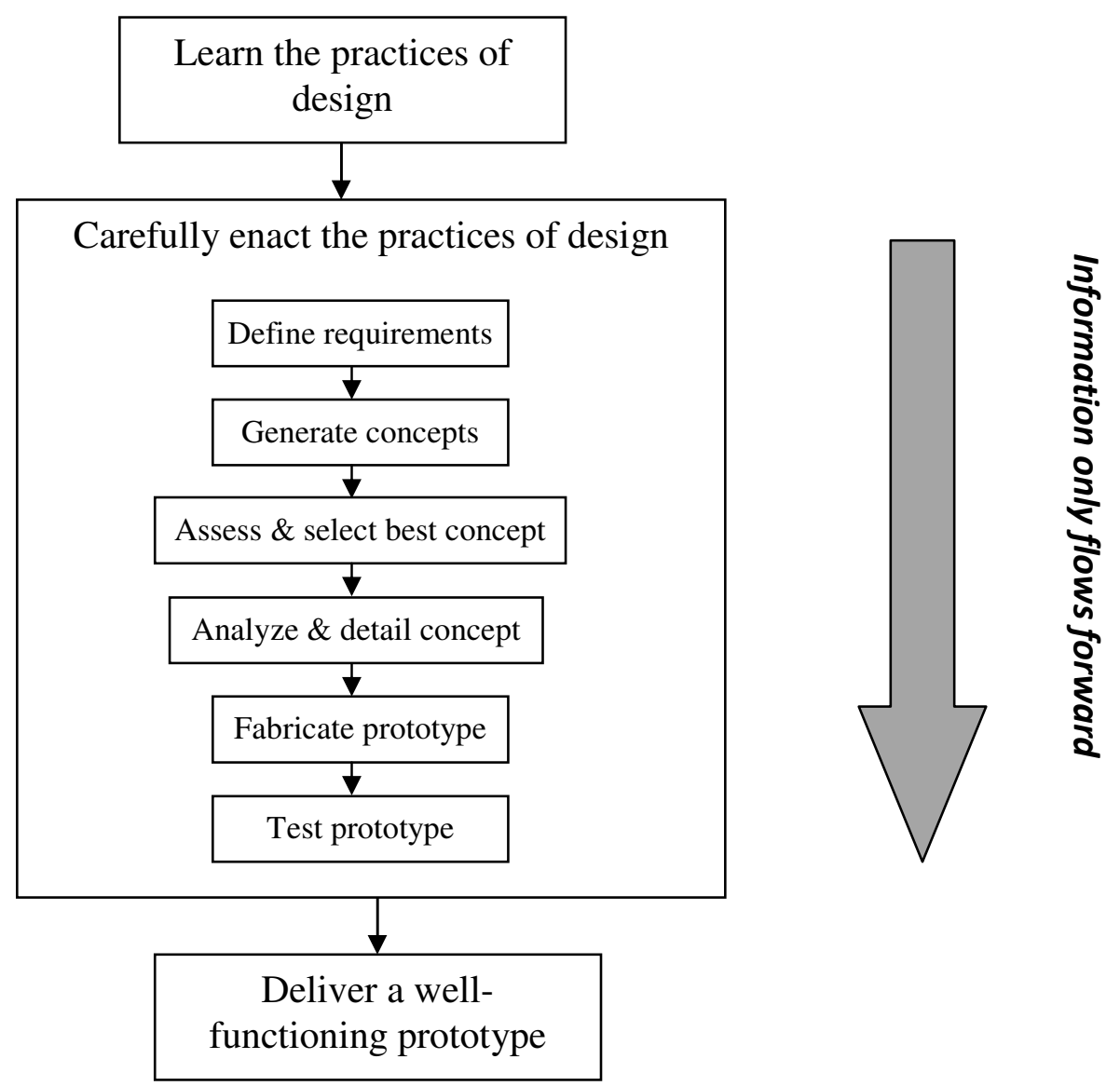

\section{Figure 1: Naïve conception of how design information flows}

A few clues to why they initially conceived of forward-only information flow appeared in their discussions. First, the textbook description of design looked tidy. "[Where did you get this idea?] ...maybe from books, it kinda makes it sound like if you set a plan out perfectly that everything will be...perfect." Second, depending on a linear flow of information is a successful strategy in other classes. "I found that...in writing English papers you get your idea and then you make... up the rest of the supporting facts from the document...you interpret it from your view point." Third, real-world constraints were never enforced before. "You're not actually building it and so you don't necessarily think about the connections...." It must also be noted that the preponderance of math, science, and engineering analysis courses earlier in the curriculum present "tidy" solutions to primarily closed-ended problems. ${ }^{6}$

From linear knowledge to product and process learning

The students initially expected design to be "tidy," but this expectation was quickly dispelled when real-life constraints were applied. For example, their first poker chip manipulator did not work as planned. All subsequent manipulators also had problems. Their camera shutter-pushing mechanism did not work. This information flowed back to them immediately upon testing. The information also came as a long serial assault. "Every time we thought we found a solution, we'd 
fix something [and then] there was something else that needed to be fixed, and finally we got through all the problems, but it took a while." Other design information also flowed back to them at other times, such as when the machinist told them their parts could not be fabricated.

The students responded to this back-flow of information by addressing design problems as they were discovered. Over time, they developed an experimental strategy of creating the design in pieces, "Do a little part, test it, do a little part, test it..." Similarly they developed the habit of conceptualizing a product in pieces by decomposing it and thinking through the details. Ultimately, this led the students to look for ways to simplify the implementation of their concepts.

This adapting to the back-flow of information can be understood as a learning process in two domains; they learned about their product and about the process of design. Figure 2 diagrams this flow of knowledge. In the column on the right are the basic design steps presented in class. The students worked through these steps fairly sequentially, employing varying levels of rigor in each. At each step, the students increased their product knowledge. When they encountered problems with their design, their knowledge of the product was challenged and (hopefully) refined. As they developed habits to resolve or avoid problematic design implementations, they increased their process knowledge. Hence product learning was, at least in part, a gatekeeper for process learning.

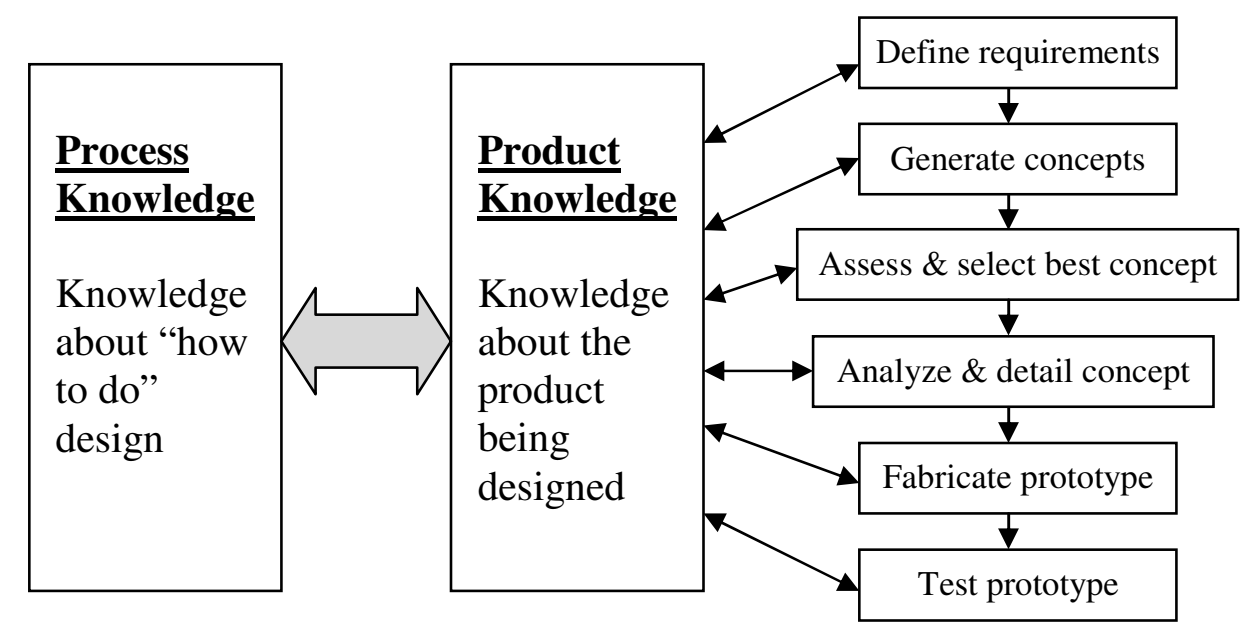

Figure 2: Knowledge flow and learning as the students enacted the design process

The student comments indicated that their product learning was significant. Many of their design habits such as, "Do a little part, test it, do a little part, test it...," were focused exclusively on increasing product learning. Their comments also suggest that a conceptual framework ${ }^{4}$ (schema) naturally developed to organize what they knew about their product. It should be noted that the students were not explicitly aware that their understanding was growing in this way. At the start of the project, their conceptual framework of product knowledge was sparse, "You see 
the problem really simply. It's just one thing instead of lots of little pieces of it." Their conceptual framework later developed to a point where they immediately knew the ripple effect of changing a single part. "We didn't want to change our designs [be]cause if you change one part of it, it wouldn't mate right with another part and would change all these different arrangements...."

The students also developed a notable misconception in their understanding of their product. The misconception involved the design of a cam-follower driven by a spring. Initially the students ignored the spring design because it was considered a lower priority than other features to design, "We were focusing on big components...." The students also ignored the spring because they assumed their spring would work, "We assumed that it would just work...."

As their design progress, their rationale for ignoring the spring also changed. The low priority status gave way to a work avoidance rationale, "We thought it would be easier [to try several springs] than calculating a spring force and things like that...." Finally the rationale became wishful thinking, "We just assumed that there would be some magical resistive force and we fixed it with a little rubber band and we assumed that that would fix our magical resistive force."

The students' misconception was very difficult to resolve. Part of this difficulty was that the students simply did not recognized the problem, "A lot of the time somebody else needed to point it out - that it wasn't going to work." Not only did the students need the problem pointed out, they needed it pointed out a few times, "You [the instructor] talked to us many times about it..." and, "[The machinist] pointed out the springs to us...." Once the students recognized their misconception they started designing alternatives, "We had first started looking at the torsional springs, but we couldn't get them to work." This led to brainstorming with the machinist and he suggested a solution, "It did the same thing as we imagined conceptually but it was something that actually worked."

This misconception showed the hallmarks of pre-existing knowledge interfering with learning, as described in the literature. ${ }^{1,2}$ First it was very robust. The students couldn't be dissuaded even though the instructor and the machinist pointed out the problem on a few occasions. Second, it deterred their learning about their product. They simply lived with an inconsistency in their understanding. Third, this misconception interfered with fixing the design, and hence interfered with further product learning.

What is truly significant about the students' misconception is that it developed in their product, not their process, knowledge. Once in their product knowledge, it prompted unsuccessful process strategies such as ignoring feedback, not examining assumptions, work avoidance, and shallow thinking. It may ultimately have contributed to developing process misconceptions. Fortunately in this case, real-world constraints forced the students to re-examine and resolve their product misconception.

This is also significant from a curricular point of view. Design classes typically do not specify learning outcomes that students develop deep knowledge of their own product. Rather the outcomes usually describe learning the process of design without reference to product knowledge. This could predispose faculty and students to give a lower priority to product 
learning. However, if product learning is even a partial gatekeeper to process learning, then lack of focus on product learning could impede the stated outcomes in process learning.

Design decision-making strategies

Satisficing ${ }^{4,7}$ is a decision-making strategy. In this strategy a person considers options one-byone and chooses the first option that meets his or her minimum criteria. This is a common strategy that people use in everyday life. It yields acceptable solutions while minimizing decision-making overhead.

The students described their dominant decision-making process as satisficing, "Normally whenever you work on something, you know, your first idea, you take it, you run with it, and that's just kind of what you use." Later, one student noted that she used her first "workable" idea, “...the first one [concept] I really didn't know what I was doing... the second one [concept] I had more of an idea so I used my second one...." In each case the students used their first option that met their minimum criteria, albeit naïve criteria.

The students also used a satisficing strategy when they ran into problems. When something didn't work, they chose the first reasonable alternative they found. "Once we tried it out, we realized that it didn't quite work like we wanted it, so... someone else would come up with like, 'Oh, what if we just scrapped that and did this?', then we'd all kinda go toward that idea."

In contrast to satisficing, the course presented the standard design process described in most textbooks. ${ }^{8,9,10,11,12,13}$ Figure 3 shows the decision-making strategies side by side. The upward arrows in the textbook decision-making process indicate that some iteration is involved. It should be noted that the students followed the textbook decision-making process per the course requirements, but fell back to satisficing to actually do their design work.

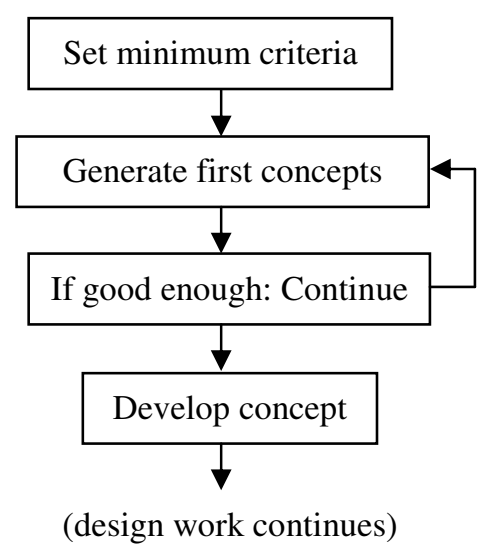

Student enacted satisficing

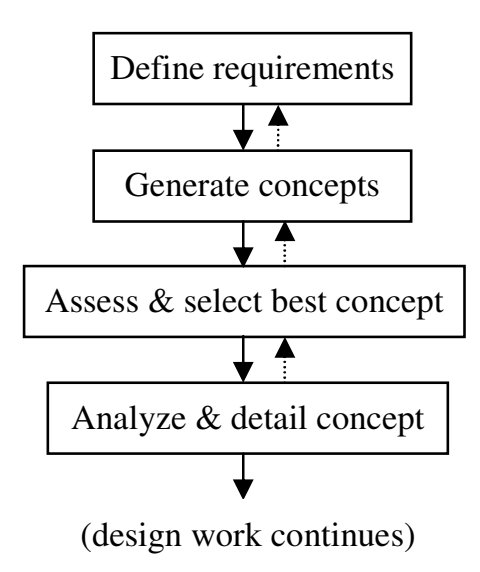

$\underline{\text { Textbook decision-making }}$

\section{Figure 3: Satisficing contrasted with textbook design process}

Student use of satisficing strategies represents a significant pedagogical hurdle. As described in the results section, the students successfully used a "run with your first idea" strategy in all 
previous courses. Furthermore, from the literature ${ }^{4}$ it is clear that satisficing is a successful strategy in everyday life. Consequently, for students to learn when and where not to use satisficing, they must have multiple significant experiences of a more successful decisionmaking strategy. Simply reiterating the value of a formal decision-making process is likely not enough.

The students noted that their first ideas were not their best. However, they did not necessarily adopt (or learn?) the formal decision strategy as shown in textbooks. Rather, they enacted a process of decomposing their product into sub-functions, designing and testing sub-functions at the lowest level, and then integrating them. Their described process could easily be accomplished using satisficing.

From a different perspective, it may be fruitful to consider how often professional engineers use satisficing, or other common heuristics, in place of formal decision-making processes. From the cognitive literature, it is clear that people rarely use highly rational decision-making processes, but rather rely on heuristics and experience. ${ }^{4}$ Why should engineers be different? From this perspective, professional engineers may frequently use satisficing, but couple it with a very rich understanding of "minimum acceptable criteria" and a wealth of previous solutions.

\section{Conclusions}

The findings in this study must be interpreted relative to the methods used. The focus group discussions with a team of four students do not give a statistically generalizable result. Rather the findings represent the design learning of those four students. However, since these specific findings align with the broader findings in the cognitive literature, they should not be considered unique or uncommon. Rather the student experiences of learning design in this study provide a partial picture of the variety of student learning experiences in design. As such, the following two findings are transferable ${ }^{14}$ to other design learning contexts.

1. Knowledge flows back to students from their own design as real-world constraints are enforced. As the students learn from their design, they develop a conceptual framework of how their design works or does not work. As this conceptual framework develops, misconceptions can also develop within that framework. These misconceptions can be very robust, require multiple interventions to resolve, and interfere with correct understanding of their design. Furthermore, these misconceptions can prompt unsuccessful design process strategies, which may deter learning the design process.

2. Students may follow a decision-making heuristic of "satisficing," that is choosing the first "good enough" option, while implement their designs. This heuristic is used by people in everyday life to streamline decisions when they lack complete information. In contrast many design textbooks describe a much more rational decision-making process. This finding suggests that the cognitive literature in heuristics and decision-making can provide a theoretical foundation for understanding why students have difficulty enacting the design process as described in textbooks.

The author wishes to thank the student participants in this study. Without their engaging discussions, this work would not be possible. 


\section{References}

1. Donovan, M. S., \& Bransford, J. D., ed. (2005). How Students Learn: Science in the Classroom. Washington, D.C.: National Academies Press.

2. Bransford, J. D., Brown, A. L., \& Cocking, R. R., ed. (2000). How People Learn: Brain, Mind, Experience, and School. Washington, D.C.: National Academies Press.

3. diSessa, A. A. (1993). "Toward an Epistemology of Physics," Cognition and Instruction, 10(2 \& 3), $105-225$.

4. Sternberg, R.J., (2003). Cognitive Psychology. $3^{\text {rd }}$ ed., Belmont, CA: Wadsworth.

5. Joyce, B., \& Weil, M. (2000). Models of Teaching ( $6^{\text {th }}$ ed.). Boston: Allyn and Bacon.

6. Sheppard, S. D., Macatangay, K., Colby, A., \& Sullivan, W. M., (2009). Educating Engineers: Designing for the Future of the Field. San Francisco: Jossey-Bass.

7. Simon, H. A. (1957). Administrative Behavior ( $2^{\text {nd }}$ ed.). Totowa, NJ: Littlefield, Adams.

8. Eggert, R. J (2005). Engineering Design. Upper Saddle River, NJ: Pearson Education, Inc.

9. Dym, C.L., and Little, L. (2003). Engineering Design: A Project-Based Introduction (2 ${ }^{\text {nd }}$ ed.). New York, NY: John Wiley.

10. Bystrom, M., and Eisenstein, B. (2005). Practical Engineering Design. Boca Raton, FL: CRC Press.

11. Ulrich, K.T., and Eppinger, S.D. (2004). Product Design and Development ( $3^{\text {rd }}$ ed.). Boston, MA: McGraw Hill.

12. Ullman, D.G. (2003). The Mechanical Design Process $\left(3^{\text {rd }}\right.$ ed.). Boston, MA: McGraw Hill.

13. Pahl, G., and Beitz, W. (1996). Engineering Design: A Systematic Approach (2 ${ }^{\text {nd }}$ ed.). London UK: Springer.

14. Leydens, J. A., Moskal, B. M., \& Pavelich, M. J. (2004). "Qualitative Methods Used in the Assessment of Engineering Education," Journal of Engineering Education, 93(1), 65-72. 